\title{
Serous cystic neoplasm of the pancreas: a multinational study of 2622 patients under the auspices of the International Association of Pancreatology and European Pancreatic Club (European Study Group on Cystic Tumors of the Pancreas)
}

B Jais, ${ }^{1}$ V Rebours, ${ }^{1} \mathrm{G}$ Malleo, ${ }^{2} \mathrm{R}$ Salvia, ${ }^{2} \mathrm{M}$ Fontana, ${ }^{2} \mathrm{~L}$ Maggino, ${ }^{2} \mathrm{C}$ Bassi, ${ }^{2}$ R Manfredi, ${ }^{2}$ R Moran, ${ }^{3,4,5}$ A M Lennon, ${ }^{3,4,5}$ A Zaheer, ${ }^{3,4,5}$ C Wolfgang, ${ }^{3,4,5}$ R Hruban, ${ }^{3,4,5} \mathrm{G}$ Marchegiani, ${ }^{6}$ C Fernández Del Castillo, ${ }^{6}$ W Brugge, ${ }^{6}{ }^{6} \mathrm{Ha}^{7}$ M H Kim, ${ }^{7}$ D Oh, ${ }^{7}$ I Hirai, ${ }_{1}^{8}$ W Kimura, ${ }^{8}$ J Y Jang, ${ }^{9}$ S W Kim ${ }_{1}^{9}$ W Jung, ${ }^{9}$ H Kang ${ }_{1}{ }^{10}$ S Y Song, ${ }^{10}$ C M Kang, ${ }^{11}$ W J Lee, ${ }^{11}$ S Crippa, ${ }^{12}$ M Falconi, ${ }^{12}$ I Gomatos, ${ }^{13}$ J Neoptolemos, ${ }^{13}$ A C Milanetto, ${ }^{14}$ C Sperti, ${ }^{14}$ C Ricci, ${ }^{15}$ R Casadei, $^{15} \mathrm{M}$ Bissolati, ${ }^{16}$ G Balzano, ${ }^{16}$ | Frigerio, ${ }^{17} \mathrm{R}$ Girelli, ${ }^{17} \mathrm{M}$ Delhaye, ${ }^{18} \mathrm{~B}^{1}$ Bernier, ${ }^{18} \mathrm{H}$ Wang, ${ }^{19}$ K T Jang, ${ }^{20}$ D H Song, ${ }^{21}$ M T Huggett, ${ }_{1}^{22}$ K W Oppong, ${ }^{22}$ L Pererva, $^{23}$ K V Kopchak, ${ }_{1}^{23}$ $\mathrm{M}$ Del Chiaro, ${ }^{24} \mathrm{R}$ Segersvard, ${ }^{24} \mathrm{~L} \mathrm{~S}$ Lee, ${ }^{25} \mathrm{D}$ Conwell, ${ }^{25} \mathrm{~A}$ Osvaldt, ${ }^{26} \mathrm{~V}$ Campos, ${ }^{26}$ $\mathrm{G}$ Aguero Garcete, ${ }^{27} \mathrm{~B}$ Napoleon, ${ }^{27}$ I Matsumoto, ${ }^{28} \mathrm{M}$ Shinzeki, ${ }^{28} \mathrm{~F}$ Bolado, ${ }^{29}$ J M Urman Fernandez, ${ }^{29}$ M G Keane, ${ }^{30}$ S P Pereira, ${ }^{30}$ I Araujo Acuna, ${ }^{31}$ E C Vaquero, ${ }^{31}$ M R Angiolini, ${ }^{32}$ A Zerbi, ${ }^{32}$ J Tang, ${ }^{33}$ R W Leong, ${ }^{33}$ A Faccinetto, ${ }^{34}$ G Morana, ${ }^{34}$ M C Petrone, ${ }^{35}$ P G Arcidiacono, ${ }^{35}$ J H Moon, ${ }^{36} \mathrm{H} \mathrm{J} \mathrm{Choi,}{ }^{36} \mathrm{R} \mathrm{S} \mathrm{Gill,}{ }^{37}$ D Pavey, ${ }^{37}$ M Ouaïssi, ${ }^{38}$ B Sastre, ${ }^{38}$ M Spandre, ${ }^{39}$ C G De Angelis, ${ }^{39}$ M A Rios-Vives, ${ }^{40}$ M Concepcion-Martin, ${ }^{40}{ }^{4}$ Ikeura, ${ }^{41} \mathrm{~K}$ Okazaki, ${ }^{41}$ L Frulloni, ${ }^{42}$ 0 Messina $^{42}{ }^{4}$ Lévy $^{1}$

For numbered affiliations see end of article.

\section{Correspondence to} Professor P Lévy, Department of Gastroenterology and Pancreatology, Beaujon Hospital, AP-HP, 100 Boulevard du Général Leclerc, 92118 Clichy Cedex, France; philippe.levy@bjn.aphp.fr

Received 22 March 2015 Revised 10 May 2015 Accepted 11 May 2015 Published Online First 4 June 2015

\section{ABSTRACT}

Objectives Serous cystic neoplasm (SCN) is a cystic neoplasm of the pancreas whose natural history is poorly known. The purpose of the study was to attempt to describe the natural history of SCN, including the specific mortality. Design Retrospective multinational study including SCN diagnosed between 1990 and 2014.

Results 2622 patients were included. Seventy-four per cent were women, and median age at diagnosis was 58 years (16-99). Patients presented with non-specific abdominal pain (27\%), pancreaticobiliary symptoms (9\%), diabetes mellitus $(5 \%)$, other symptoms $(4 \%)$ and/or were asymptomatic (61\%). Fifty-two per cent of patients were operated on during the first year after diagnosis (median size: $40 \mathrm{~mm}(2-200)), 9 \%$ had resection beyond 1 year of follow-up (3 years (1-20), size at diagnosis: $25 \mathrm{~mm}$ (4$140))$ and $39 \%$ had no surgery (3.6 years (1-23), $25.5 \mathrm{~mm}$ (1-200)). Surgical indications were (not exclusive) uncertain diagnosis $(60 \%)$, symptoms $(23 \%)$, size increase $(12 \%)$, large size $(6 \%)$ and adjacent organ compression (5\%). In patients followed beyond 1 year $(n=1271)$, size increased in 37\% (growth rate: $4 \mathrm{~mm} /$ year), was stable in $57 \%$ and decreased in $6 \%$. Three serous cystadenocarcinomas were recorded. Postoperative mortality was $0.6 \%(n=10)$, and SCN's related mortality was $0.1 \%(n=1)$.

\section{Significance of this study}

What is already known on this subject?

- Serous cystic neoplasm is a cystic neoplasm of the pancreas whose natural history is poorly known.

- Following guidelines, serous cystic neoplasm should be resected in patients with disabling symptoms or when the cyst diagnosis is uncertain.

- Several predictors of complications have been proposed: initial cyst size, growth rate, oligocystic/macrocystic variant, a history of other non-pancreatic malignancies and patients' age.

- There is no consensus about the strategical management between follow-up and surgery.

What are the new findings?

- Serous cystic neoplasm is seldom symptomatic.

- It has a slow growth and is associated with a very low risk of new onset symptoms.

- Malignant progression is very rare.

- Disease-specific mortality of serous cystic neoplasm is almost nil. 
Significance of this study

\section{How might it impact on clinical practice in the foreseeable future?}

- It is important to achieve a complete workup including CT scan, MRI and endoscopic ultrasonography in order to get an accurate diagnosis of serous cystic neoplasm.

- Surgical treatment should be proposed in a minority of patients, only for uncertain diagnosis, significant and related symptoms or exceptionally when exists concern with malignancy.

- This study supports initial conservative management for the majority of patients with $\mathrm{SCN}$.

Conclusions After a 3-year follow-up, clinical relevant symptoms occurred in a very small proportion of patients and size slowly increased in less than half. Surgical treatment should be proposed only for diagnosis remaining uncertain after complete workup, significant and related symptoms or exceptionally when exists concern with malignancy. This study supports an initial conservative management in the majority of patients with SCN.

Trial registration number IRB 00006477.

\section{INTRODUCTION}

Due to the widespread use and increasing advances in crosssectional imaging, the discovery of asymptomatic cystic tumours of the pancreas has increased. The prevalence is reported to be between $2.6 \%$ and $19.6 \% .^{12}$

Serous cystic neoplasm (SCN) represents $10-16 \%$ of cystic pancreatic lesions. ${ }^{3}{ }^{4}$ Mucinous neoplasms (mucinous cystic neoplasm and intraductal papillary mucinous neoplasm (IPMN)) are potentially malignant, whereas SCN is benign in nearly all the cases. ${ }^{5}$ However, there is no consensus about the need for surgical resection or surveillance strategies for SCN. Some centres argue that $\mathrm{SCN}$ should undergo surgical resection due to the risk of malignant progression, the risk of mechanical complications due to their size and location. ${ }^{6} 7$ In addition, a significant number of patients with SCN undergo resection as they are misdiagnosed as pre-malignant or malignant neoplasms. ${ }^{8}$ In contrast, other centres, following guidelines, only recommend resection in patients with disabling symptoms due to the SCN or when the cyst diagnosis is uncertain. ${ }^{5} 9$

In order to improve SCN management, predictors of complications have been proposed: initial cyst size, growth rate, oligocystic/macrocystic variant, a history of other non-pancreatic malignancies and patient age. ${ }^{10-12}$ The absence of consensus highlights the lack of knowledge about the natural history of SCN with a large number of cases and a sufficient follow-up. The goal of this study was to analyse a very large international cohort of surgically resected and non-resected SCNs in order to describe the natural history. In this setting, the primary objectives were to describe the disease-specific mortality, the growth rate during follow-up and the risk of malignancy.

\section{PATIENTS AND METHODS}

\section{Study population}

We conducted a retrospective, international and multicentre study under the auspices of the International Association of
Pancreatology (IAP), the European Pancreatic Club (EPC) and the European Study Group on Cystic Tumors of the Pancreas. Members of the IAP and EPC were contacted via email.

Some of the recruited patients may have been previously published in series from participating centres. ${ }^{12-14}$

\section{Inclusion criteria}

Inclusion criteria were all histologically or radiologically highly suspected SCN, diagnosed between 1990 and 2014.

Radiological and histological diagnostic criteria are detailed below. In cases where the diagnosis remained in doubt, endoscopic ultrasonography (EUS) diagnostic criteria (detailed below), with or without cyst fluid aspiration, were used. SCN data had to be filled between January 2013 and February 2014.

\section{Exclusion criteria}

Patients with Von Hippel-Lindau disease, incomplete records, follow-up $<1$ year (in non-operative patients) and cases with unclear diagnosis were excluded. Unclear SCN diagnosis was defined as cases in which there was an uncertain radiological or histological diagnosis, or probable misdiagnosis not clarified after email requests for more precise data.

\section{Data collection and study groups}

Data were collected through an online form. Two data points were scheduled: one at the first imaging study (DP1), the second at the last imaging study or at the time of surgical resection or death (DP2). Abdominal CT and/or abdominal MRI and/ or EUS were requested at DP1, and also at DP2 for the nonoperated patients.

Follow-up period extended between the first (DP1) and the last imaging study or surgery (DP2).

We divided the cohort into three groups. Group 1 (G1) included patients undergoing surgery less than a year after the diagnosis, group 2 (G2) included patients who underwent surgery $>1$ year after diagnosis and group 3 (G3) included nonoperated patients with a follow-up $>1$ year. The duration of 1 year for groups 2 and 3 was chosen in order to have a minimum follow-up to observe morphological changes.

Demographic (age, gender), clinical (symptoms), radiographic and endoscopic (tumour size, location, cystic pattern, local compression), surgical (type of operation, location, surgical mortality) and pathological (tumour size, lymph node involvement, evidence of local aggressiveness and/or metastasis) data were collected. Surgical morbidity was not recorded since the study was retrospective.

\section{Radiological and endosonographic features}

Four morphological SCN patterns were distinguished: microcystic, macrocystic, mixed microcystic and macrocystic and solid (figure 1). ${ }^{13}$ Microcystic pattern was defined as multiple cysts measuring $<2 \mathrm{~cm}$ separated by thin fibrous septa giving sometimes a honeycomb aspect. ${ }^{15}$ Macrocystic type were cysts $\geq 2 \mathrm{~cm} .{ }^{16}$ Mixed microcystic and macrocystic type was defined by a combination of a microcystic and macrocystic pattern. Solid SCN was a tumour without cystic lesions distinguishable on cross-sectional imaging. In case of atypical imaging such as an unilocular macrocystic type, the following criteria were requested: polycyclic outlines, thin wall, no tubular structure or communication with pancreatic duct system. ${ }^{17}$

When multiple imaging studies were performed, the largest cyst size was chosen at DP1 and the more recent ones at DP2. Tumour growth was calculated by dividing the difference in size between DP2 and DP1 to the follow-up period ( $\mathrm{mm} /$ year). 


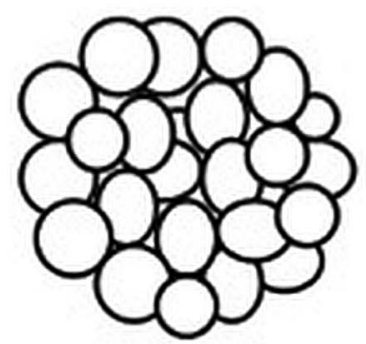

Microcystic type

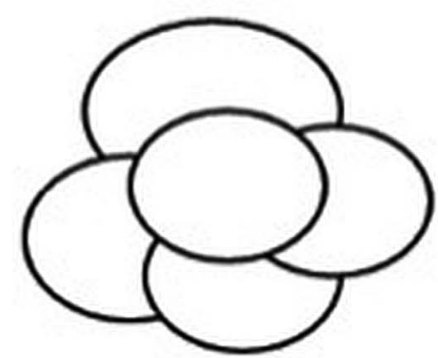

Macrocystic type

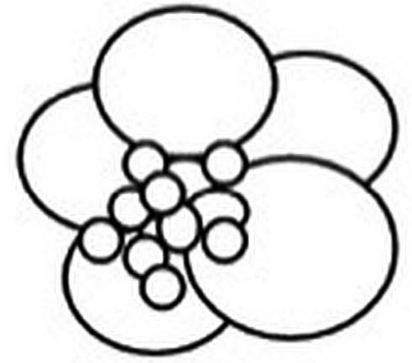

Mixed type

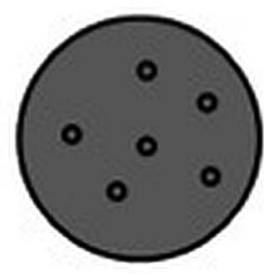

Solid type

Figure 1 Four morphological serous cystic neoplasm patterns were distinguished: microcystic, macrocystic, mixed microcystic and macrocystic and solid. $^{13}$

The diagnosis of SCN at EUS was based on the presence of a myriad of microcysts ( $2 \mathrm{~mm}$ or less) separated by thin septa, which sometimes appear as 'layered' and a thin cyst outline wall. ${ }^{18} 19$ In the absence of microcystic appearance, a low carcinoembryonic antigen (CEA) level in the cystic fluid was considered specific of $\mathrm{SCN}^{20}$ No central reviewing of imaging procedures was performed.

\section{Pathology}

SCNs were histologically defined by the presence of cysts lined by a single, uniform layer of cuboidal, glycogen-rich 'serous cells'. 21

Malignant SCN was defined by distant metastasis beyond pancreatic and peripancreatic bed. ${ }^{21}$

Considering Khashab et al's ${ }^{14}$ definition, we defined locally aggressive tumours as tumours that invaded surrounding structures, vessels and/or peripancreatic lymph nodes without distant metastasis.

No central reviewing of pathological specimen was performed.

\section{Statistical analysis}

Qualitative variables are presented as frequencies (\%) and continuous data as median (range) as appropriate. In case of missing data, ' $n$ ' indicates the number of patients with available data. Comparisons of qualitative data were performed using the $\chi^{2}$ or Fisher's test and continuous data were compared using the Mann-Whitney test. To determine whether initial size influenced tumour growth, a correlation of these two parameters was performed using the Spearman's test. To such end, we only took into account the lesions that actually grew. All tests were two sided. A p value $<0.05$ was considered significant. All statistical analyses were performed using SPSS V.19.0 (SPSS for Mac, IBM, Chicago, Illinois, USA).

\section{RESULTS}

\section{General and imaging characteristics}

-In total, 2799 cases were identified. Also, -177 cases were excluded because of incomplete data $(n=75)$, follow-up $<1$ year for non-operated patients $(n=67)$ and a doubtful diagnosis $(n=35)$. Ultimately, 2622 patients from 23 countries and 71 centres (including 31 surgical centres) were included. Seventy-four per cent of the patients were women, and median age at diagnosis was 58 years (16-99) (table 1). The diagnosis was based on pathological analysis in 1590 cases, highly suspected diagnosis on radiological features in 785 cases and with the help of cyst fluid analysis in 247 cases. The morphological patterns in the whole population were microcystic in $45 \%$, macrocystic in $32 \%$, mixed microcystic and macrocystic in $18 \%$ or solid in $5 \%$ of cases. In the 785 cases where diagnosis relied only on radiological data, these percentages were respectively microcystic in $55 \%$, macrocystic in $24 \%$, mixed in $19 \%$ or solid in $2 \%$. Cystic calcifications were present in $15 \%$. The tumour was located in the head/uncinate process in $40 \%$, in the body in $34 \%$ and in the tail in $26 \%$ of cases. SCN had a lobulated shape in $58 \%$. Upstream dilated main pancreatic duct was present in $11 \%$ of cases.

\section{Medical or surgical treatment}

Among the 2622 patients, 61\% underwent surgical resection including 52\% within 1 year following diagnosis $(\mathrm{G} 1, \mathrm{n}=1351)$ and $9 \%$ after 1 year of follow-up (G2, $n=239$, median follow-up: 3.0 years (1-20)). Conservative management was undertaken in $39 \%$ of the patients $(G 3, n=1032$, median follow-up: 3.6 years (1-23)) (table 1). Sixty-seven per cent of $\mathrm{G} 2+\mathrm{G} 3$ patients $(\mathrm{n}=850)$ have been followed between 1 and

Table 1 Baseline characteristics

\begin{tabular}{lc}
\hline & Overall \\
\hline Sex, $\mathrm{n}(\%)$ & \\
$\quad$ Male & $683(26)$ \\
Female & $1939(74)$ \\
Median age at diagnosis, years (range) & $58(16-99)$ \\
Symptoms, $\mathrm{n}(\%)$ & \\
$\quad$ Asymptomatic & $1610(61)$ \\
$\quad$ Symptomatic & $1012(39)$ \\
Tumour location, $\mathrm{n}(\%)$ & \\
$\mathrm{n}=2491$ & \\
Head/uncinate & $985(40)$ \\
Body & $860(34)$ \\
Tail & $646(26)$ \\
Schematic pattern, $\mathrm{n}(\%)$ & \\
$\mathrm{N}=2516$ & \\
Microcystic & $1127(45)$ \\
Macrocystic & $814(32)$ \\
Mixed microcystic/macrocystic & $455(18)$ \\
Solid & $120(5)$ \\
Initial median tumour diameter, mm (range) & $31(1-238)$ \\
Management, $\mathrm{n}(\%)$ & \\
Operated <1 year (G1) & $1351(52)$ \\
Operated $>1$ year (G2) & $239(9)$ \\
Non-operated (G3) & $1032(39)$ \\
\hline
\end{tabular}




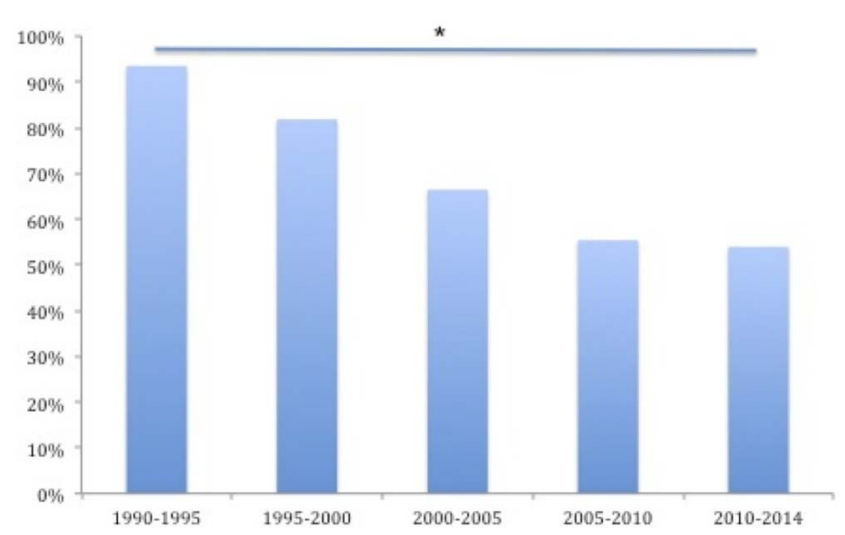

Figure 2 The resection rate decreased over time from $94 \%$ between 1990 and 1995 to $54 \%$ between 2010 and $2014(p<0.01)$.

5 years, 27\% $(n=342)$ between 5 and 10 years, 5\% $(n=63)$ between 10 and 15 years and 1.2\% $(n=16)$ between 15 and 20 years.

Among the 10 centres that included $>40$ cases, resection rate ranged from $24 \%$ to $93 \%$. The resection rate decreased over time from 94\% between 1990 and 1995 to 54\% between 2010 and $2014(\mathrm{p}<0.01)$ (figure 2).

Among the operated patients (G1 and G2; $n=1590)$, indications for surgery (more than one indication was possible) were unclear diagnosis $(n=950 ; 60 \%)$, symptoms $(n=370 ; 23 \%)$, increasing tumour diameter $(n=193 ; 12 \%)$, initial large size $(n=97 ; 6 \%)$ and adjacent organ compression $(n=82 ; 5 \%)$.

In the group of patients operated for unclear diagnosis $(n=951)$, the preoperative evaluation included CT, MRI and EUS in 13\%, CT and MRI in 17\%, CT and EUS in 15\%, MRI and EUS in 2\%, CT alone in 47\%, MRI alone in 5\% and EUS alone in $1 \%$.

The remaining patients (53\%) had only one cross-sectional imaging (CT or MRI or EUS) before surgery. When EUS was performed, fine needle aspiration (FNA) was associated in 30\% of cases.

In the group of patients operated for symptoms $(n=366)$, $242(66 \%)$ presented with non-specific symptoms and 124 (34\%) with pancreaticobiliary symptoms.

\section{Symptoms}

At diagnosis, patients had non-specific abdominal pain (27\%), pancreaticobiliary symptoms (9\%), diabetes mellitus (5\%), other symptoms (4\%; abdominal mass, asthenia, nausea and vomiting)

Table 2 Symptoms, initial tumour diameter and tumour growth in operated patients less than a year after the diagnosis (group 1), in operated patients $>1$ year after diagnosis (group 2) and in non-operated patients (group 3)

\begin{tabular}{|c|c|c|c|c|}
\hline & G1 ( $n=1351)$ & $\begin{array}{l}G 2 \\
(n=239)\end{array}$ & $\begin{array}{l}G 3 \\
(n=1032)\end{array}$ & $\begin{array}{l}p \\
\text { Value* }\end{array}$ \\
\hline Symptoms, n (\%) & $704(52) t \ddagger$ & $75(31)$ & $233(23)$ & $<0.001$ \\
\hline $\begin{array}{l}\text { Initial diameter, mm } \\
\text { (range) }\end{array}$ & $40(2-238) \dagger \ddagger$ & $25(4-140)$ & $25.5(1-200)$ & 0.354 \\
\hline $\begin{array}{l}\text { Tumour growth, } \\
\text { mm/year (range) }\end{array}$ & & $4(0-41.5)$ & $1(0-27)$ & $<0.001$ \\
\hline
\end{tabular}

${ }^{*}$ Represents intergroup's $p$ value.

tRepresents significant $(p<0.001)$ value for comparison between $G 1$ and $G 2$ groups.

$\ddagger$ Represents significant $(p<0.05)$ value for comparison between $\mathrm{G1}$ and $\mathrm{G} 3$ groups. or were asymptomatic (61\%). Patients were more frequently symptomatic in G1 compared with G2 and G3 (52\% vs 31\% and 23\%, respectively; $\mathrm{p}<0.001$ ) (table 2). With increasing cyst size, patients were more frequently symptomatic (including specific and non-specific symptoms) $(\mathrm{p}<0.001)$ (figure 3 ). However, there was no clear size cut-off associated with symptoms.

Among the 1271 G2 and G3 patients, 963 were asymptomatic at DP1. In this group, 104 (11\%) became symptomatic at DP2 (non-specific abdominal pain $(n=69)$, pancreaticobiliary symptoms $(n=33)$ and/or diabetes mellitus $(n=10))$.

\section{Tumour size and growth rate}

Overall initial median cyst diameter was $31 \mathrm{~mm}$ (1-238). The initial diameter was significantly higher in G1 than in G2 ( $40 \mathrm{~mm}$ vs $25 \mathrm{~mm}$; p <0.001), and than in G3 (40 vs $25.5 \mathrm{~mm}$; $\mathrm{p}<0.05$ ) (table 2). Among the patients who underwent surveillance (G2 and G3; n=1271), 724 (57\%) SCNs remained stable in size, $476(37 \%)$ increased in size (tumour growth: $4 \mathrm{~mm} /$ year) and $71(6 \%)$ decreased in size, most of the time after EUS FNA. Diameter at DP2 was $40 \mathrm{~mm}(0-170)$ and $29 \mathrm{~mm}(0-240)$ in G2 and G3, respectively.

Tumour growth was higher in G2 than in G3 (4 vs $1 \mathrm{~mm} /$ year; $\mathrm{p}<0.001)$. Tumour growth was correlated with initial tumour size (correlation coefficient $=0.211 ; \mathrm{p}<0.001)$ (figure 4). Tumour $<4 \mathrm{~cm}(\mathrm{n}=976)$ had a slower growth compared with those $\geq 4 \mathrm{~cm} \quad(n=295)(1.25$ vs $2.7 \mathrm{~mm} /$ year, $\mathrm{p}=0.002)$. Tumour growth was not associated with radiological pattern $(\mathrm{p}=0.89)$ or age $(\mathrm{p}=0.08)$.

\section{Aggressive behaviour}

Three serous cystadenocarcinomas $(0.1 \%)$ were reported: two patients had liver metastasis (one synchronous, one metachronous) and one had distant hepatic artery lymph nodes metastases. These three patients were symptomatic (non-specific abdominal pain $(n=2)$, jaundice $(n=1))$. The cystadenocarcinoma and the metastases were surgically resected for each patient. One patient was lost to follow-up after 1 year, one was still alive after 9 years then lost to follow-up. The last patient with lymph node metastases had adjuvant chemotherapy and was still alive at 1 year.

The diameter of serous cystadenocarcinoma was 71, 100 and $170 \mathrm{~mm}$. Among 1590 operated patients, 18 patients with SCN were considered as locally aggressive, including 14 from one centre: invasion of regional organs $(n=6)$, regional lymph node involvement $(n=3)$, peripancreatic vessels $(n=8)$ and perineural area $(n=1)$.

\section{SCN-specific mortality and operative mortality}

Among the 1032 non-operated patients, one died of pneumonia after an endoscopic retrograde cholangiopancreatography indicated for SCN-related jaundice. Disease-specific mortality was $0.1 \%$ in G3. If the three patients with malignant SCN were considered to have died, disease-specific mortality would have been $0.4 \%$.

Reported operative mortality was $0.6 \%$. Ten patients died within 30 postoperative days (all but one after 2000) from pneumonia $(n=3)$, septic shock $(n=2)$, colon perforation $(n=1)$, retroperitoneal haemorrhage $(n=1)$, hepatic failure $(n=1)$ and two for unknown reasons. Whipple procedure mortality was $1.5 \%$ (7 deaths/461) and left pancreatectomy mortality was $0.2 \%$ (2/861). Mortality in G2 was $0.8 \%$ and in G1 $0.6 \%$ (not significant). 


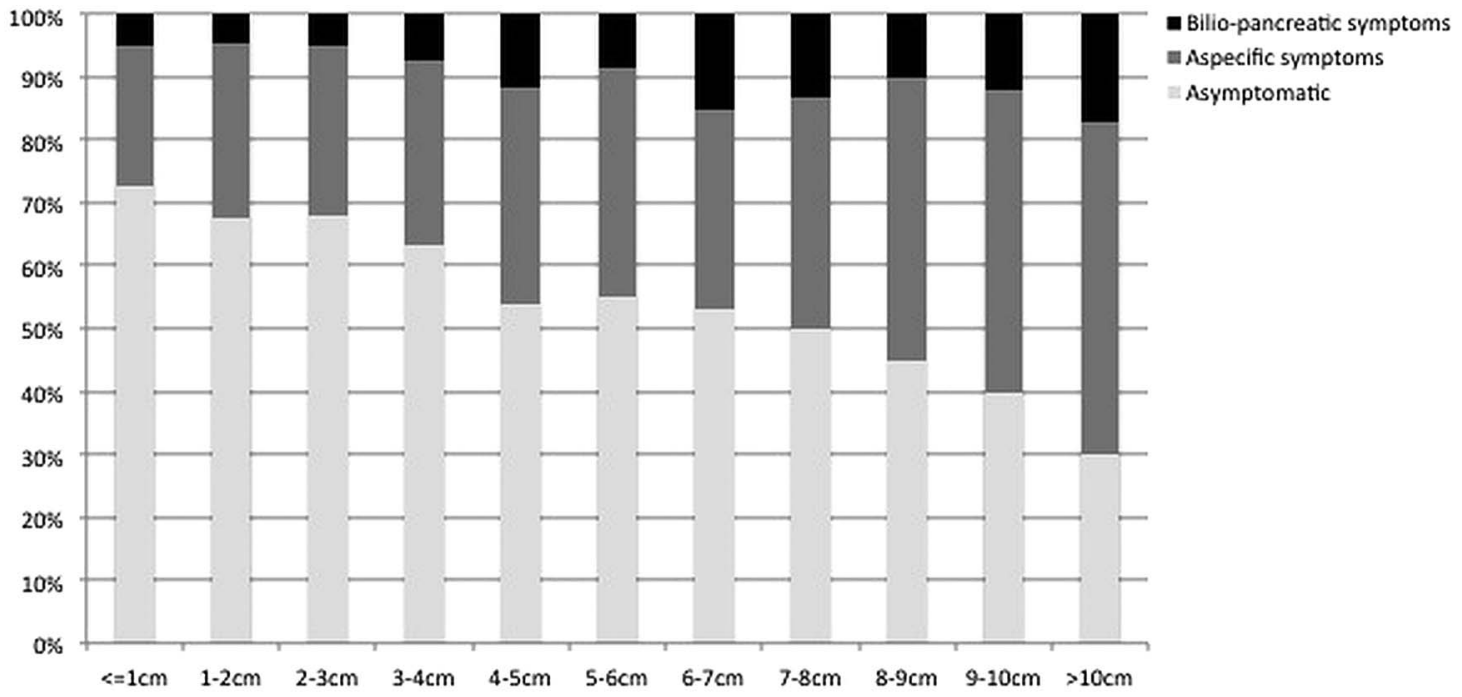

Figure 3 With increasing cyst size, patients were more frequently symptomatic (including specific and non-specific symptoms) ( $<<0.001$ ).

\section{DISCUSSION}

This work, performed under the auspices of the IAP and EPC, is the largest cohort of histologically or radiologically proven SCNs. Although the way of recruitment and data records are opened to criticisms, the size of the cohort allows to draw some important conclusions. The main results underscore that $\mathrm{SCN}$ are benign in nearly all cases, indolent with slow growth and rarely become symptomatic. SCN-specific mortality is nearly nil.

Currently, the management of SCN remains controversial. The difficulty to have an accurate preoperative diagnosis, the presence of symptoms supposedly related to SCN, the risk of new onset symptoms and the risk of malignant transformation are the major arguments raised for surgical intervention. ${ }^{6-8}$ On the other hand, the indolence of the tumour and the significant

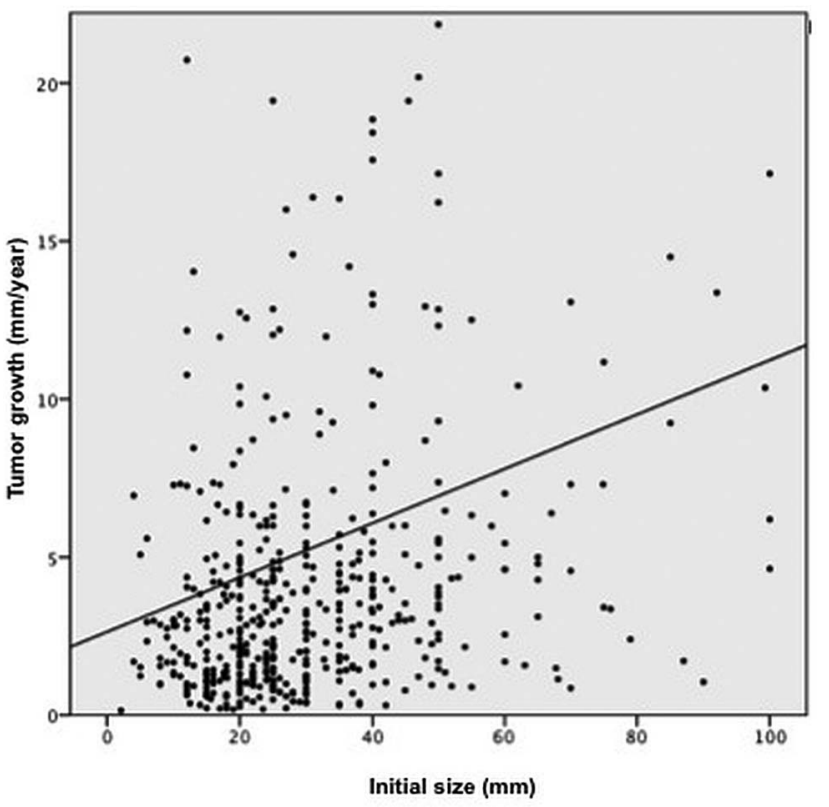

Figure 4 Tumour growth was higher in $\mathrm{G} 2$ than in $\mathrm{G} 3$ (4 vs $1 \mathrm{~mm} /$ year; $p<0.001)$. Tumour growth was correlated with initial tumour size (correlation coefficient $=0.211 ; \mathrm{p}<0.001$ ). morbidity and mortality of pancreatic surgery are strong arguments in favour of a conservative attitude.

The first and main issue in SCN management is to accurately diagnose them. CT and MRI are the two imaging modalities usually used for the diagnosis of pancreatic cysts. Despite knowledge and technological advances, establishing an accurate diagnostic can be difficult. In this study, the majority of patients were operated on because of diagnostic uncertainty (60\%). But only $13 \%$ of patients in this group had CT, MRI and EUS performed, while $34 \%$ had two imaging studies. It is noticeable that these imaging procedures were not always available at the beginning of recruitment. Blinded studies have shown that diagnostic accuracy by CT and MRI for SCN ranged from $27 \%$ to $91 \%$, while accuracy for pancreatic cysts ranged from $43 \%$ to $64 \% .^{22-24}$ When cross-sectional imaging does not allow definitive diagnosis, EUS can provide supplemental information thanks to high-resolution images. ${ }^{25-27}$ If a diagnostic doubt remains, the additional benefit of EUS resides with the ability to perform cyst FNA for a fluid analysis. ${ }^{28}$ Low CEA levels with different thresholds had an excellent specificity for SCN diagnosis. ${ }^{20} 29{ }^{30}$ However, low cyst fluid CEA have also been reported in IPMNs and in neuroendocrine tumours. ${ }^{31} 32$ Moreover, EUS-FNA is not always technically feasible and it can be difficult to obtain sufficient fluid for biochemical analysis. ${ }^{33}$ In this study, FNA was performed with EUS in 30\% of cases. Nowadays, surgery for uncertain diagnosis when the preoperative diagnosis workup is insufficient does not appear as an acceptable option. If there is no clear diagnosis after a CT and/or MRI, EUS should be performed. And if a doubt still remains, the association with FNA for cyst fluid analysis is necessary if technically feasible. Surgery is indicated if all investigations have been completed and there is still a doubt with a pancreatic neoplasm. The reduction of the resection rate with time underscores the progress in technology and knowledge of imaging semiology. It is likely that molecular genetic analysis of cyst fluid such as the presence of a VHL mutation, vascular endothelial growth factor dosage or confocal laser endomicroscopy could lead to a more accurate diagnosis. $^{34-36}$

Even when an SCN is diagnosed preoperatively, centres have different approaches depending on cultural trends (surgical units vs medical ones), tumour size, presence of symptoms and risk of new onset of symptoms. Several centres select patients 
for surgery considering the tumour size and the growth rates. In a small monocentric series, tumours $<4 \mathrm{~cm}$ had a slower growth rate than tumours $\geq 4 \mathrm{~cm} \quad(1.2$ vs $20 \mathrm{~mm} /$ year; $\mathrm{p}=0.0002) .{ }^{10}$ Recent studies showed no correlation between tumour size and growth rate. ${ }^{11} 12$ In the present study, growth rate was significantly higher for tumours $\geq 4 \mathrm{~cm}(2.7$ vs $1.25 \mathrm{~mm}$ /year). The growth rate interpretation is limited by our short follow-up and the absence of more than one interval imaging. Moreover, this method assumed a linear growth rate instead of a curvilinear growth rate, which can better reflect the reality. ${ }^{11}$ We also observed a slight increase of symptom rate in large SCN. The question of whether a large size per se or a slow-growing SCN are an indication for surgery remains open. Unlike a recent study, macrocystic variant and patients' age were not associated with higher growth rate. ${ }^{12}$

Some authors consider symptomatic $\mathrm{SCN}$ as an indication for surgery. ${ }^{5}$ However, it is important to ensure that the tumour is responsible for the symptoms. In the present study, $27 \%$ of patients complained of non-specific abdominal pain. Only $9 \%$ of patients presented pancreaticobiliary symptoms directly related to the tumour. The risk of new onset symptoms was low as well, with only $11 \%$ of patients becoming symptomatic during follow-up.

The risk of malignant progression influences management. Since 1989, 28 cases of serous cystadenocarcinoma have been reported in the literature. ${ }^{37}$ As of now, there is no consensus about the definition of serous cystadenocarcinomas. Considering Bosman et al's ${ }^{21}$ definition, malignant $\mathrm{SCNs}$ are characterised by distant metastasis beyond pancreatic and peripancreatic bed. Whether locally aggressive SCN defined by invaded surrounding structures should be considered as benign, malignant or intermediate stage still remains in debate. ${ }^{14}$ Eighteen cases of locally aggressive tumours were recorded. Of these, 14 were provided from an unique centre. This might be explained by discrepant definition of these stages. It is the reason why we do not draw any conclusion about the prevalence of this entity in the entire cohort.

Three serous cystadenocarcinomas $(0.2 \%)$ were recorded in the present study. The proportion of serous cystadenocarcinomas was lower than usually described in the literature (around $1-3 \%){ }^{6}{ }^{21}$ Tumour diameter was significantly larger compared with non-malignant group. Serous cystadenocarcinomas seemed to have a low aggressive behaviour with a monitoring up to 9 years. It is much lower than those for branch duct IPMNs for which international experts recommended surveillance in the absence of worrisomes. ${ }^{38}$ When balanced with the operative risk of mortality and morbidity, these results suggest that the risk of malignant transformation should not be the sole indication for surgery.

Recently, some authors have advocated early active surgical strategy considering the risk of complications of an asymptomatic SCN and the improvement of pancreatic surgery. ${ }^{7}$ This strategy implies the need to evaluate the risk-benefit balance between follow-up and surgery. Within the limits of a short median follow-up, we observed a very low specific mortality and rate of new onset symptoms. Operative mortality was much lower than reported in high-volume centres (around 1-3\%) and was probably underestimated in this self-reporting study. ${ }^{39} 40$ Moreover, short-term and long-term pancreatic surgical morbidity remains high with pancreatic fistulae, exocrine pancreatic insufficiency and/or diabetes mellitus in around one-third of cases.

Due to the very low rate of new events in patients with SCN, it is difficult to prospectively follow-up patients during a long time. We aimed at recruiting retrospectively a large number of patients from expert centres to answer as far as possible the most critical issues. Imaging studies and pathological slides were not centrally reviewed. We could not make sure that cyst measurements were uniform across all centres. Follow-up was short but similar to the other studies, except one. ${ }^{12}$ Study strengths are the very large number of patients that included both operated and non-operated SCNs. If there was any essential missing information or diagnosis doubt, centres were systematically contacted and remaining doubtful cases were excluded.

In conclusion, we describe the natural history and specific mortality of SCNs in a very large cohort of patients from expert centres, with a median 3 years' follow-up in non-operated patients. This study suggests that SCN is almost always a benign and indolent tumour, seldom symptomatic, with slow growth and very low risk of new onset symptoms including malignant progression. Inside this interval of time, disease-specific mortality was almost nil. Surgical treatment should be proposed in a minority of patients, only for uncertain diagnosis remaining after complete workup including CT scan, MRI and EUS, significant and related symptoms or exceptionally when concern with malignancy exists. This study supports initial conservative management for the majority of patients with SCN.

\section{Author affiliations}

'Department of Gastroenterology and Pancreatology, Beaujon Hospital, AP-HP, Clichy, France

${ }^{2}$ The Pancreas Institute, G.B. Rossi Hospital, University of Verona Hospital Trust, Verona, Italy

${ }^{3}$ Division of Gastroenterology and Hepatology, The Johns Hopkins University School of Medicine, Baltimore, Maryland, USA

${ }^{4}$ Division of Surgery, The Johns Hopkins University School of Medicine, Baltimore,

Maryland, USA

${ }^{5}$ Department of Pathology, The Sol Goldman Pancreatic Cancer Research Center, The Johns Hopkins University School of Medicine, Baltimore, Maryland, USA

${ }^{6}$ Departments of Surgery and Pathology, Massachusetts General Hospital, Harvard Medical School, Boston, Massachusetts, USA

${ }^{7}$ Department of Gastroenterology, Asan Medical Center, University of Ulsan College of Medicine, Seoul, Korea

${ }^{8}$ First Department of Surgery, Yamagata University Faculty of Medicine, Yamagata, Japan

${ }^{9}$ Department of Surgery, Seoul National University College of Medicine, Seoul, Korea ${ }^{10}$ Division of Gastroenterology, Department of Internal Medicine, Yonsei University College of Medicine, Seoul, Korea

${ }^{11}$ Department of Surgery, Yonsei University College of Medicine, Pancreaticobiliary

Cancer Clinic, Yonsei Cancer Center, Severance Hospital, Seoul, Korea

${ }^{12}$ Pancreatic Surgery Unit, Department of Surgery, Polytechnic University of Marche Region, Ancona-Torrette, Italy

${ }^{13}$ NIHR Pancreas Biomedical Research Unit, Department of Molecular and Clinical

Cancer Medicine, Royal Liverpool University Hospital, Institute of Translational

Medicine, University of Liverpool, Liverpool, UK

${ }^{14}$ Department of Surgery, Oncology and Gastroenterology, 3rd Surgical Clinic,

University of Padua, Padua, Italy

${ }^{15}$ Department of Medical and Surgical Sciences (DIMEC), Alma Mater Studiorum-

University of Bologna, S. Orsola-Malpighi Hospital, Bologna, Italy

${ }^{16}$ Pancreatic Surgery Unit, IRCCS San Raffaele Scientific Institute, Milan, Italy

${ }^{17}$ Hepato-Pancreato-Biliary Unit, Pederzoli Hospital, Peschiera del Garda, Italy

${ }^{18}$ Department of Gastroenterology, Hepatopancreatology and GI Oncology, Erasme

University Hospital, Université Libre de Bruxelles, Brussels, Belgium

${ }^{19}$ Institute of Hepatopancreatobiliary Surgery, Southwest Hospital, Third Military

Medical University, Chongqing, China

${ }^{20}$ Department of Pathology, Samsung Medical Center, Sungkyunkwan University

School of Medicine, Seoul, Korea

${ }^{21}$ Department of Pathology, Gyeongsang National University School of Medicine, Jinju, Korea

${ }^{22}$ Hepato-Pancreato-Biliary Unit, Freeman Hospital, Newcastle upon Tyne, UK

${ }^{23}$ National Institute of Surgery and Transplantology named after Shalimov, Kiev, Ukraine

${ }^{24}$ Division of Surgery, Department of Clinical Science, Intervention and Technology (CLINTEC), Karolinska Institutet at Center for Digestive Diseases, Karolinska

University Hospital, Stockholm, Sweden

${ }^{25}$ Division of Gastroenterology, Brigham and Women's Hospital, Boston,

Massachusetts, USA

${ }^{26}$ Hospital de Clínicas de Porto Alegre, Universidade Federal do Rio Grande do Sul, Porto Alegre, Brazil 
${ }^{27}$ Hôpital Privé Mermoz, Gastroentérologie, Lyon, France

${ }^{28}$ Division of Hepato-Biliary-Pancreatic Surgery, Department of Surgery, Kobe University Graduate School of Medicine, Kobe, Japan

${ }^{29}$ Gastroenterology Department, Hospital de Navarra, Pamplona, Spain

${ }^{30}$ Department of Gastroenterology and Hepatology, University College Hospital, London, UK

${ }^{31}$ Department of Gastroenterology, Hospital Clinic, CIBEREHD, IDIBAPS, University of Barcelona, Barcelona, Spain

${ }^{32}$ Department of Pancreatic Surgery, Humanitas Research Hospital, Rozzano, Milan, Italy

${ }^{33}$ Gastroenterology and Liver Services, Concord Hospital, Sydney, New South Wales, Australia

${ }^{34}$ Radiological Department, General Hospital Cá Foncello, Treviso, Italy

${ }^{35}$ Division of Gastroenterology and Gastrointestinal Endoscopy, San Raffaele Scientific Institute, Milan, Italy

${ }^{36}$ Department of Internal Medicine, Digestive Disease Center and Research Institute, SoonChunHyang University School of Medicine, Bucheon, Korea

${ }^{37}$ Department of Gastroenterology, Bankstown-Lidcombe Hospital, Bankstown, New South Wales, Australia

${ }^{38}$ Department of Digestive Surgery, Timone Hospital, Marseille, France

${ }^{39}$ Gastrohepatology Department, San Giovanni Battista Molinette Hospital, University of Turin, Turin, Italy

${ }^{40}$ Gastroenterology Department, Hospital de la Santa Creu i Sant Pau, Institut de Reçerca - IIB Sant Pau, Universitat Autònoma de Barcelona, Barcelona, Spain

${ }^{41}$ The Third Department of Internal Medicine, Division of Gastroenterology and Hepatology, Kansai Medical University, Osaka, Japan

${ }^{42}$ Department of Medicine, Pancreas Center, University of Verona, Verona, Italy

Correction notice This article has been corrected since it published Online First. Author I Neoptolemos name has been corrected. Affiliation 7 has been amended; 'FC: statistical analysis' has been included in the Contributors section and Cauchy F acknowledged in the Acknowledgement section.

Acknowledgements The authors thank other contributors for their fantastic work to include SCN: Antonini F, Macarri G (A.Murri Hospital, Fermo, Italy), Khaoudy I, Regimbeau JM (Amiens University Hospital, France), Rupjyoti T (Asian Institute of Gastroenterology, Hyderabad, India), Cauchy F (Beaujon Hospital, Clichy, France) Mannami T (Chugoku Central Hospital, Fukuyama, Japan), Ausloos F, Deprez P (Cliniques Universitaires Saint-Luc, Bruxelles, Belgium), Han J, Kim HG (Catholic University of Daegu, Korea), Lee JK, Lee CG (Dongguk University Ilsan Hospital, Goyang, Korea), Azzinnaro M, Filauro M (E. O. Ospedali Galliera, Genoa, Italy), Jesse Fest, Henri Braat (Erasmus Medical Center, Rotterdam, Netherlands), Litvin A, Trosko V (Gomel Regional Clinical Hospital, Gomel, Belarus), Frampton AE, Jiao LR (Hammersmith Hospital, London, UK), Ardengh JC, Martins-Neto MM (Hospital das Clínicas da Faculdade de Medicina de Ribeirão Preto, Sao Paulo, Brazil), Gutiérrez SC, Marchi L (Hospital Nacional Posadas, Buenos Aires, Argentina), López-Serrano A (Hospital Universitario Dr. Peset, Valencia, Spain), Molero X, Montenegro A (Hospital Vall d'Hebron, Barcelona, Spain), Choi EK, Jeong SU (Jeju National University Hospital, Jeju-Do, Korea), Choi HS, Cheon YK (Konkuk University Hospital, Seoul, Korea), Bezmarevic M, Perisic N (Military Medical Academy, Belgrade, Serbia), Fujii T, Yamada S (Nagoya University Graduate School of Medicine, Japan), loka T, Ashida R (Osaka Medical Center for Cancer and Cardiovascular Diseases, Japan), Marcucci S, Beltempo P (Ospedale Santa Chiara, Trento, Italy), Galeev S, Rubtsov M (Saint Luke Clinical Hospital, Saint-Pertersburg, Russia), Capurso G, Delle Fave G (San Andrea Hospital, Roma, Italy), Shimamura H (Sendai Medical Center, Japan), Almarhabi A, Baillargeon JD (Sherbrooke University, Canada), Kikuyama M, Kurokami T (Shizuoka General Hospital, Japan), Burkert J, Abu Hilal M (Southampton University Hospital, UK), Aoki T, Morikawa T (Tohoku University, Sendai, Japan), Pelaez-Luna M, Uscanga-Dominguez LF (Universidad Nacional Autonoma de Mexico, Mexico), Scherber PR, Glanemann M (Universitaetsklinikum des Saarlandes, Homburg, Germany), Urayama S, Singh I (University of California Davis Medical Center, Sacramento, USA), Neri V,

Lapolla F (University of Foggia, Italy), Dominguez-Muñoz JE, Lariño-Noia J (University Hospital of Santiago de Compostela, Spain), Balázs A, Hegyi P (University of Szeged, Hungria).

Contributors BJ: study concept and design; acquisition of data; analysis and interpretation of data; drafting of the manuscript; critical revision of the manuscript for important intellectual content; statistical analysis. VR: study concept and design; critical revision of the manuscript for important intellectual content; statistical analysis. GM, RS, $M F, L M, C B, R M, R M, A M L, A Z, C W, R H, G M, C F D C, W B, Y H, M H K, D O, I H, W K, J Y J$, SWK, WJ, HK, SYS, CMKang, WJL, SC, MF, IG, JN, ACM, CS, CR, RC, MB, GB, IF, RG, $M D, B B, H W, K T J, D H S, M T H, K W O, L P, K V K, M D C, R S, L S L, D C, A O, V C, G A G, B N$, IM, MS, FB, JMUF, MGK, SPP, IAA, ECV, MRA, AZ, JT, RWL, AF, GM, MCP, PGA, JHM, HJC, RSG, DP, MO, BS, MS, CGDA, MAR-V, MC-M, TI, KO, LF, OM: study concept; acquisition of data; critical revision of the manuscript for important intellectual content. FC: statistical analysis. PL: study concept and design; acquisition of data; analysis and interpretation of data; drafting of the manuscript; critical revision of the manuscript for important intellectual content; statistical analysis; study supervision.
Competing interests AML is consultant for Boston scientific. PL is consultant for Abbvie and Mayoly Spindler.

Patient consent Obtained.

Ethics approval Institutional Review Board (IRB 00006477) of HUPNVS, Paris 7 University, AP-HP.

Provenance and peer review Not commissioned; externally peer reviewed.

\section{REFERENCES}

1 Laffan TA, Horton KM, Klein AP, et al. Prevalence of unsuspected pancreatic cysts on MDCT. Am J Roentgenol 2009;191:802-7.

2 Zhang X, Mitchell D, Dohke M. Pancreatic Cysts: Depiction on Single-Shot Fast Spin-Echo MR Images 1. Radiology 2002;223:547-53.

3 Kosmahl M, Pauser U, Peters K, et al. Cystic neoplasms of the pancreas and tumor-like lesions with cystic features: A review of 418 cases and a classification proposal. Virchows Arch 2004;445:168-78

4 Valsangkar NP, Morales-Oyarvide V, Thayer SP, et al. 851 resected cystic tumors of the pancreas: a 33-year experience at the Massachusetts General Hospital. Surgery 2012;152:S4-12.

5 Del Chiaro M, Verbeke C, Salvia R, et al. European experts consensus statement on cystic tumours of the pancreas. Dig Liver Dis 2013:45:703-11.

6 Strobel $\mathrm{O}, \mathrm{Z}^{\prime}$ graggen K, Schmitz-Winnenthal FH, et al. Risk of Malignancy in Serous Cystic Neoplasms of the Pancreas. Digestion 2003;68:24-33.

7 Hwang HK, Kim H, Kang CM, et al. Serous cyst adenoma of the pancreas: appraisal of active surgical strategy before it causes problems. Surg Endosc 2012;26:1560-5.

8 Horvath KD, Chabot JA. An aggressive resectional approach to cystic neoplasms of the pancreas. Am J Surg 1999;178:269-74.

9 Khalid A, Brugge W. ACG practice guidelines for the diagnosis and management of neoplastic pancreatic cysts. Am J Gastroenterol 2007:2339-49.

10 Tseng J, Warshaw A, Sahani D. Serous cystadenoma of the pancreas. Ann Surg 2005;242:413-21.

11 El-Hayek KM, Brown N, O'Rourke C, et al. Rate of growth of pancreatic serous cystadenoma as an indication for resection. Surgery 2013;154:794-800; discussion $800-2$

12 Malleo G, Bassi C, Rossini R, et al. Growth pattern of serous cystic neoplasms of the pancreas: observational study with long-term magnetic resonance surveillance and recommendations for treatment. Gut 2012:61:746-51.

13 Kimura W, Moriya T, Hanada K, et al. Multicenter study of serous cystic neoplasm of the Japan pancreas society. Pancreas 2012:41:380-7.

14 Khashab M, Shin EJ, Amateau S, et al. Tumor size and location correlate with behavior of pancreatic serous cystic neoplasms. Am I Gastroenterol 2011;106:1521-6.

15 Johnson C. Cystic pancreatic tumors: CT and sonographic assessment. Am J Radiol 1988;151:1133-8.

16 Choi J, Kim M, Lee JY, et al. Typical and atypical manifestations of the Serous Cystadenoma of the Pancreas: Imaging findings with Pathologic Correlation. AJR 2009::136-42.

17 Cohen-Scali F, Vilgrain V, Brancatelli G, et al. Discrimination of unilocular macrocystic serous cystadenoma from pancreatic pseudocyst and mucinous cystadenoma with CT: initial observations. Radiology 2003;228:727-33.

18 Barthet M, Palazzo L, Chemali M, et al. Management of cystic pancreatic lesions found incidentally. Endoscopy 2007;39:926-8.

19 O'Toole D, Palazzo L, Hammel P, et al. Macrocystic pancreatic cystadenoma: the role of EUS and cyst fluid analysis in distinguishing mucinous and serous lesions. Gastrointest Endosc 2004:59:823-9.

20 Hammel $\mathrm{P}$, Levy $\mathrm{P}$, Voitot $\mathrm{H}$, et al. Preoperative cyst fluid analysis is useful for the differential diagnosis of cystic lesions of the pancreas. Gastroenterology 1995:108:1230-5.

21 Bosman F, Carneiro F, Hruban R. WHO classification of tumours of the digestive system. IARC WHO Classif Tumours 2010;43:3.

22 Curry C, Eng J, Horton K. CT of primary cystic pancreatic neoplasms: can CT be used for patient triage and treatment? Am J Radiol 2000;175:99-103.

23 Correa-Gallego C, Ferrone CR, Thayer SP, et al. Incidental pancreatic cysts: do we really know what we are watching? Pancreatology 2010;10:144-50.

24 Visser BC, Yeh BM, Qayyum A, et al. Characterization of cystic pancreatic masses: relative accuracy of CT and MRI. AJR Am J Roentgenol 2007;189:648-56.

25 Brugge WR. Role of endoscopic ultrasound in the diagnosis of cystic lesions of the pancreas. Pancreatology 2001;1:637-40.

26 Adimoolam V, Sanchez MJ, Siddiqui UD, et al. Endoscopic ultrasound identifies synchronous pancreas cystic lesions not seen on initial cross-sectional imaging. Pancreas 2011:40:1070-2.

27 Khashab MA, Kim K, Lennon AM, et al. Should we do EUS/FNA on patients with pancreatic cysts ? The incremental diagnostic yield of EUS over CT/MRI for prediction of cystic neoplasms. Pancreas 2013;42:717-21.

28 Frossard J, Amouyal P. Performance of endosonography-guided fine needle aspiration and biopsy in the diagnosis of pancreatic cystic lesions. Am J Gastroenterol 2003;98:1516-24. 


\section{Pancreas}

29 Van der Waaij L, van Dullemen $H$, Porte $R$, et al. Cyst fluid analysis in the differential diagnosis of pancreatic cystic lesions: a pooled analysis. Gastrointest Endosc 2005;62:383-9.

30 Brugge W, Lewandrowski K. Diagnosis of pancreatic cystic neoplasms: a report of the cooperative pancreatic cyst study. Gastroenterology 2004;126:1330-6.

31 Park WG, Mascarenhas R, Palaez-Luna M, et al. Diagnostic performance of cyst fluid carcinoembryonic antigen and amylase in histologically confirmed pancreatic cysts. Pancreas 2011;40:42-5.

32 Yoon WJ, Daglilar ES, Pitman MB, et al. Cystic pancreatic neuroendocrine tumors: endoscopic ultrasound and fine-needle aspiration characteristics. Endoscopy 2013;45:189-94.

33 De Jong K, Poley J-W, van Hooft JE, et al. Endoscopic ultrasound-guided fine-needle aspiration of pancreatic cystic lesions provides inadequate material for cytology and laboratory analysis: initial results from a prospective study. Endoscopy 2011;43:585-90.

$34 \mathrm{Wu}$ J, Jiao Y, Dal Molin M, et al. Whole-exome sequencing of neoplastic cysts of the pancreas reveals recurrent mutations in components of ubiquitin-dependent pathways. Proc Natl Acad Sci USA 2011;108:21188-93.
35 Yip-Schneider MT, Wu H, Dumas RP, et al. Vascular endothelial growth factor, a novel and highly accurate pancreatic fluid biomarker for serous pancreatic cysts. J Am Coll Surg 2014;218:608-17.

36 Napoleon B, Lemaistre A-I, Pujol B, et al. A novel approach to the diagnosis of pancreatic serous cystadenoma : needle-based confocal laser endomicroscopy. Endoscopy 2015;47:1-7.

37 Wasel B, Keough V, Huang W. Histological percutaneous diagnosis of stage IV microcystic serous cystadenocarcinoma of the pancreas. BMJ Case Rep 2013;2013: pii: bcr2012007924.

38 Tanaka M, Fernández-del Castillo C, Adsay V, et al. International consensus guidelines 2012 for the management of IPMN and MCN of the pancreas. Pancreatology 2012;12:183-97.

39 Balcom JH IV, Rattner DW, Warshaw AL, et al. Ten-year experience with 733 pancreatic resections. Arch Surg 2001;136:391.

40 Kleeff J, Diener MK, Z'graggen $\mathrm{K}$, et al. Distal pancreatectomy: risk factors for surgical failure in 302 consecutive cases. Ann Surg 2007;245:573-82. 


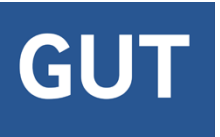

Serous cystic neoplasm of the pancreas: a multinational study of 2622 patients under the auspices of the International Association of Pancreatology and European Pancreatic Club (European Study Group on Cystic Tumors of the Pancreas)

B Jais, V Rebours, G Malleo, R Salvia, M Fontana, L Maggino, C Bassi, R Manfredi, R Moran, A M Lennon, A Zaheer, C Wolfgang, R Hruban, G Marchegiani, C Fernández Del Castillo, W Brugge, Y Ha, M H Kim, D Oh, I Hirai, W Kimura, J Y Jang, S W Kim, W Jung, H Kang, S Y Song, C M Kang, W J Lee, S Crippa, M Falconi, I Gomatos, J Neoptolemos, A C Milanetto, C Sperti, C Ricci, R Casadei, M Bissolati, G Balzano, I Frigerio, R Girelli, M Delhaye, B Bernier, H Wang, K T Jang, D H Song, M T Huggett, K W Oppong, L Pererva, K V Kopchak, M Del Chiaro, R Segersvard, L S Lee, D Conwell, A Osvaldt, V Campos, G Aguero Garcete, B Napoleon, I Matsumoto, M Shinzeki, F Bolado, J M Urman Fernandez, M G Keane, S P Pereira, I Araujo Acuna, E C Vaquero, M R Angiolini, A Zerbi, J Tang, R W Leong, A Faccinetto, G Morana, M C Petrone, P G Arcidiacono, J H Moon, H J Choi, R S Gill, D Pavey, M Ouaïssi, B Sastre, M Spandre, C G De Angelis, M A Rios-Vives, M Concepcion-Martin, T Ikeura, K Okazaki, L Frulloni, O Messina and P Lévy

Gut 2016 65: 305-312 originally published online June 4, 2015 doi: 10.1136/gutjnl-2015-309638

Updated information and services can be found at:

http://gut.bmj.com/content/65/2/305

These include:

References This article cites 38 articles, 2 of which you can access for free at: http://gut.bmj.com/content/65/2/305\#BIBL

Email alerting service

Receive free email alerts when new articles cite this article. Sign up in the box at the top right corner of the online article.

Topic Articles on similar topics can be found in the following collections Collections

Pancreas and biliary tract (1936)

To request permissions go to:

http://group.bmj.com/group/rights-licensing/permissions

To order reprints go to:

http://journals.bmj.com/cgi/reprintform

To subscribe to BMJ go to:

http://group.bmj.com/subscribe/ 


\section{Notes}

To request permissions go to:

http://group.bmj.com/group/rights-licensing/permissions

To order reprints go to:

http://journals.bmj.com/cgi/reprintform

To subscribe to BMJ go to:

http://group.bmj.com/subscribe/ 